\title{
Why do Countries Knowingly Sign Ineffective Treaties? The Case of High Seas Fishing
}

\author{
Paul Hallwood*
}

\begin{abstract}
States Parties signing and ratifying the 1982 fishing Convention and 1995 Agreement did so knowing they would be ineffective in the stated aim of efficiently managing high seas straddling and highly migratory fish stocks. It is argued that both coastal states and distant water fishing nations signed on because they gained international recognition of their 200-mile exclusive economic zones but that coastal states looked forward to concessions by distant water fishing nations on the management of straddling stocks. These concessions could include compulsory arbitration of disputes; allow prosecutions of illegal activity of foreign fishing boats in coastal state courts; withdraw shipmasters licenses if found to be overfishing; and to encourage better surveillance by costal states by requiring any fines levied by a foreign court to be transferred to the coastal state offended against. Improved collaboration between countries, better surveillance, and increased sanctions are all needed.
\end{abstract}

Key words : fisheries agreement, fisheries convention, high seas, overfishing, repeated game, straddling stocks, treaty formation

* Professor, Department of Economics, University of Connecticut, Storrs, CT, USA. E-mail: cpaulhallwood@gmail.com Received August 14, 2021; Received in revised form October 12, 2021; Accepted October 14, 2021 


\section{Introduction}

The ineffectiveness of high seas fisheries management occurs despite the 1982 U.N. Convention on the Law of the Sea (hereafter the "Convention"), and the 1995 Agreement for the Implementation of the Provisions of the Convention Relating to the Conservation and Management of Straddling Fish Stocks and Highly Migratory Fish Stocks (the "Agreement"). Both include Articles aimed at responsible high seas fishery management and to this end they support the maintenance of high seas governance institutions known as 'regional fishery organizations' of which there are 24, falling into three classes: those that promote scientific research, those that concentrate on international policy coordination, and those known as regional fisheries management organizations (RFMOs) that are meant to manage fisheries in a sustainable way (Sydnes, 2001).

Sydnes (2001) notes that "disputes settlement mechanisms have had limited impact on regional fisheries cooperation" (p. 358) largely owing to the reluctance of states to surrender some sovereignty. The mechanisms of decisionmaking by consensus and making decisions only advisory, allow a member of a RFMO to abide by only what it wants to abide by; and if decision-making is by majority vote, a county can always make an 'objection', and thereby not abide by any clause not to its liking. These features of RFMO are entirely in keeping with the nature of customary and treaty law (Hallwood, 2014, chapter 1), that is, agreeing to international public law is a voluntary act.

Cullis-Suzuki and Pauly (2010), examine the performance of 18 regional fish management organizations that have management powers scoring each of them out of 10 on 26 different measures of effectiveness. The average score across all questions was 5.7 which, for example, meant that RFMO did not get as far as 'executing performance reviews' which, of course, implied that it was near impossible to implement 'tangible, positive changes' in policy. It is not surprising therefore that using the example of the International Commission for the Conservation of Atlantic Tuna (ICCAT), biomass in all eight tuna biomasses was down, in 6 cases by about 70\%. Cullis-Suzuki and Pauly (2010) also found that the biomass trend was downward for most species under RFMO 'management' in all geographic areas. As an example, reasons why in the Northwest Atlantic Fisheries Organization (NAFO) is ineffective are stated by Churchill (2001): since the mid-1990s violations have steadily increased, non-compliance includes intentional fishing for species under moratoria, exceeding quotas, misreporting catches - by area and by species, improper use of fishing gear (e.g., mesh sizes), fishing in areas closed to fishing, failure to employ independent and impartial fisheries observers, and interference with NAFO inspectors, observers or evidence. The Canadian government was disappointed with flag state enforcement saying that flag state follow-up was ineffective and inadequate.

According to data reported by Schiller et al. (2018), the top ten high seas fishing nations over the ten years to 2011 were, China ( $17 \%$ of the high seas catch), 
Taiwan (12.0\%), Chile (8.1\%), Indonesia (6.6\%), Spain (6.2\%), Republic of Korea (6.1\%), Japan (5.5\%), Ecuador (4.4\%), India (3.0\%) and Philippines (2.8\%) which, together, accounted for almost $72 \%$ of the total high seas catch. ${ }^{1}$ All of these countries, except Taiwan, have signed both the Convention and the Agreement (United Nations, 2021). Other relevant data are that 39 fish and invertebrate species make up $99.5 \%$ of the high seas catch, with only one species, Antarctic toothfish, being caught exclusively on the high seas. The rest of the high sea's species are straddling stocks being caught both on the high seas and in adjoining Exclusive Economic Zones (EEZs). The economically most important of these straddling stocks are tuna, billfish, small pelagic fishes, pelagic squids, toothfish, and krill.

According to a Canadian study, the secretariats running the various RFMOs are weak and essentially have no authority. ${ }^{2}$ Why do member countries allow this? This paper asks why do countries sign treaties that create ineffective international law. On the face of it this is irrational. However, it will be argued that this is not necessarily the case. At issue is why have largely ineffective management institutions - the RFMOs - been initiated by two international Agreements that by 2001 had received sufficient ratifications to have become international law? Indeed, Vicuña (1999) points out that as long ago as 1958 it was generally accepted at the first United Nations Conference on the Law of the Sea (UNCLOS I) that customary rights to freedom of fishing on the high seas should be modified to promote the common good. However, international public law is voluntary. Thus, according to the Vienna Convention on the Law of Treaties (signed 1969, ratified 1980), countries can choose whether to sign a treaty and if they do so, they can choose which clauses to agree to or to take reservations against. For example, if a RFMO includes fish catch quotas, a signatory can take a reservation against it so that it does not have to limit its catch. ${ }^{3}$

\section{Some Possible Answers}

The answer offered in this paper to the question 'why sign ineffective treaties?' in the context of high seas fishing is cast in terms of the players locking themselves into a repeated game in which only one side wants a definitive conclusion. In other words, the problem is historical in both origin and process.

The high seas fishing games are played between coastal states, CSs, and distant water fishing nations, DWFNs. In support of this view see Boyle (1999), Hannesson (1995), Kaitala and Lindroos (1998), and Munro (2009). Flewwelling and Cullinan (2000) describe the strict legal constraints on coastal states under the

\footnotetext{
1 The Schiller et al. (2018) data source was the Sea Around Us (2021).

2 See Canadian A Report of the Standing Senate Committee on Fisheries and Oceans (2003).

3 For further details on international public law and fisheries management see Hallwood (2014) chapter 1.
} 
Convention and the Agreement when it comes to managing straddling stocks beyond their EEZs. They also point out that the fishing boats of some DWFNs fish for straddling stocks with impunity. "Of particular note and special pertinence today, is the economic temptation to register DWFN vessels in national registers when there is no capability to control the activities of the "new flag" vessels. Some of these "new flag" vessels operate in internationally sensitive areas of the world without appropriate attention to conservation" (p. 45). DWFNs are reluctant to restrict access to straddling stocks using quotas, closed seasons, closed areas or by any other means. It is the coastal states that press for effective high seas governance because high seas open access can and does severely degrade their own management efforts. Both high and low income coastal states are adversely affected by overfishing by distant water fishing nations. As an example, in 1995 there was the "turbot war" between Canada and Spain - supported by the European Union (Springer, 1997). And Gagern and van den Bergh (2013) argue that fishing agreements between some low income tropical island countries and distant water fishing nations are failing efficiently to manage straddling stocks because the CSs have insufficient policing resources.

The contention here is that both CSs and DWFNs signing the 1982 Convention benefited from the Convention through the extension of their rights to the 200-mile EEZs. But the creation of EEZs left open the matter of straddling stocks. Even though at least some CSs saw that distant water fishing of straddling stocks could complicate their own management of fish stocks in their EEZ's they were willing to sign the Convention even with weak rules governing straddling stocks. ${ }^{4}$ Knowing that coastal states put greater weight on obtaining an agreement on the EEZ than on reaching agreement on straddling stocks, DWFNs argued for and got weak rules governing straddling stocks fisheries. ${ }^{5}$

Another consideration is that there was another "player" at the table prior to the signing of the 1982 Convention: the 'common heritage of mankind doctrine', largely supported by low-income and landlocked countries. However, these countries were in weak bargaining positions. Enclosure and the creation of sovereign rights over ocean space had, by the mid-1970s, already won out over the 'common heritage' doctrine (Eckert, 1979). Had the 'common heritage' doctrine been robust, it is possible that a more rational high seas fishing management regime would have been put in place - one that would not have compromised CS' management of fish stocks within their EEZs.

That CSs signed the Convention did not mean that they did not want to reform and develop it in subsequent rounds of negotiation - the negotiations leading to the 1995 fish stocks Agreement being a case in point, as too continuing

4 On the matter of 'weak rules' that make arbitration between CS and DWFN ineffective see Romano (2001).

5 The recently signed Agreement to Prevent Unregulated High Seas Fisheries in the Central Arctic Ocean, that entered into force June 25, 2021, is an international agreement between ten countries, including the USA and the Republic of Korea, to protect the area from commercial fishing. However, as no fishing currently occurs in this ice covered ocean, none of the signatories were giving up any current economic values. See United States Department of State (2021). 
negotiations in the RFMOs. However, having got what they wanted in the Convention - that is, weak governance of high seas fishing - DWFNs continue to insist on maintaining weak high seas governance regimes.

Possible answers to the question 'why are the Convention and the Agreement ineffective?' include: i) no or only small penalties for non-compliance written into the agreements; ii) no or inadequate policing of the ocean space covered by the agreement, and iii) no compensation paid to a coastal state by a distant water fishing nation that is guilty of overfishing for straddling stocks.

These three features turn a cooperative game (with its legally binding connotations and presumed objective of reaching the social surplus-maximizing equilibrium) into a non-cooperative game in the sense that individual countries are free to choose their profit maximizing actions regardless of prior commitments, and regardless of the social interest. When any of these three situations occur, only a strong sense of moral commitment can over-ride self-interest in what remains in effect a non-cooperative prisoner's dilemma game - where 'cheating', rather than cooperation, is the optimal outcome.

When a treaty is strong enough, it can indeed create a cooperative game aimed at maximizing the social surplus. That is, the players must agree on enforcement and penalty mechanisms. If such a treaty came into force, signatories' behaviors would be modified when the expected punishments are greater than the expected gain from cheating.

There is also the matter of time preference that feeds into the determination of the present value of expected future payoffs from cooperation. The well-known folk theorem applies to non-cooperative games, such as the prisoner's dilemma game discussed below. It says that if any outcome to a game that gives a payoff to each player that exceeds the short-run payoff, then a discount factor exists close enough to one to ensure a Nash equilibrium in the repeated game. In other words, in the prisoner's dilemma, the cooperate solution dominates the defect-defect solution. But this is not sustainable in the short-run (one-play) game, because each player does better by defecting individually. A problem is that there are many strategies that can be played in repeated games. Game theorists propose some special cases -- naive cooperation, grim cooperation, and tit-for-tat. In naive cooperation, a player cooperates forever no matter what the other player does. In the grim strategy, a player cooperates if the other player cooperates, but once the opponent defects, then both countries defect forever. In tit-for-tat, a player cooperates at the beginning and then does whatever its opponent did in the last round. In the following discussion the simplifying assumption is made that the discount factors are not high enough to encourage long run cooperation. 


\section{Treaty Formation, Cooperative and Non-Cooperative Games}

Attention now turns to the importance of policing and the imposition of penalties in moving from the non-cooperative to the cooperative equilibrium.

In a prisoners' dilemma game, the idea of a treaty is to move from the Nash equilibrium cheat/cheat to the Pareto optimum, comply/comply, payoffs in Table $1^{6}$.

Table 1. Prisoners' dilemma

\begin{tabular}{l|c|c|c}
\hline \multicolumn{2}{c}{} & \multicolumn{2}{c}{ Distant water fishing nation } \\
\cline { 3 - 4 } \multicolumn{2}{c|}{} & Comply & Cheat \\
\hline \multirow{2}{*}{ Coastal state } & Comply & 2,2 & 0,3 \\
\cline { 2 - 4 } & Cheat & 3,0 & 1,1 \\
\hline
\end{tabular}

A treaty does this by making the return to cheating less than the return to comply - as in Table 2. The latter is achieved through a 'fine', $F$ (or, more generally, 'punishments', upon which a monetary value can be placed).

Table 2. Payoffs with a fine for cheating

\begin{tabular}{|c|c|c|c|}
\hline & & \multicolumn{2}{|c|}{ Distant water fishing nation } \\
\hline & & Comply & Cheat \\
\hline \multirow{2}{*}{ Coastal state } & Comply & 2,2 & $0,1.5$ \\
\hline & Cheat & $1.5,0$ & 1,1 \\
\hline
\end{tabular}

The fine must be large enough to reduce the payoff to cheating from 3 to less than 2 in the payoff matrix of Table 2 such that comply/comply is the better of two Nash equilibriums. (Note that in this new matrix there is an assurance game with two Nash equilibriums - the treaty is used to make the socially superior (comply/comply) the one that will be chosen).

In Table 2 the fine for cheating is 1.5 . But as there will be some probability that cheating will not be detected it is the expected fine, $E(F)$, that must equal 1.5, more strictly $>1.0$. Notice that if one player cheats, the other player has an incentive to cheat too (payoff of 1 with cheating is better than payoff of zero if one complies and the other cheats). If the complier did not also switch to cheating on the treaty rules, it would be a "sucker".

However, to get over the "sucker problem" it is theoretically possible to change the structure of the payoffs in Table 2 to those in Table 3.

6 The numbers in the payoff matrix could be either monetary values (in millions of dollars) or ordinal utility values. The use of numbers rather than algebraic symbols (such as $a>b, c>d$ etc.) is preferred here for didactic reasons. 
Table 3. Payoffs with a fine for cheating and compensation for the complier

\begin{tabular}{|c|c|c|c|}
\hline & & \multicolumn{2}{|c|}{ Distant water fishing nation } \\
\hline & & Comply & Cheat \\
\hline \multirow{2}{*}{ Coastal state } & Comply & 2,2 & $1.5,1.5$ \\
\hline & Cheat & $1.5,1.5$ & 1,1 \\
\hline
\end{tabular}

The payoffs in Table 3 are the same as in Table 2 except for the change that the payoff from complying while the other cheats is increased from 0 to 1.5. In this case, even if the other player cheats, the payoff to complying remains greater than from cheating $(1.5>1)$.

How such a change in payoffs could be accomplished is by transferring the fine, of 1.5, paid by the cheater, to the complier. Thus, a fine-withcompensation system could get over the 'sucker' problem, so inducing compliers to continue playing comply even in the face of cheating. Notice that under the 1982 Convention and the Straddling Stocks Agreement of 1995, it is the flag state that levies fines. Hence, even if fines were large and are paid by a vessel caught cheating, the return on cheating is retained by the flag state. Moreover, the fine may, to some extent, be returned to the company that paid the fine by way of subsidies on the cost of vessels or ships labor. ${ }^{7}$

The size of the expected fine, $E(F)$, rather than the fine itself, is crucial. A large fine that has low probability of being imposed is likely to have little impact on cheating behavior. Fines need to be larger the smaller is the probability of being detected.

Beginning with the simplest model:

$$
E(F)=\operatorname{Pr}_{\text {DETECT. }} F
$$

where $\operatorname{Pr}_{D E T E C T}$ is the probability of being detected cheating, and $\mathrm{F}$ is the monetary value of the fine imposed. ${ }^{8}$

Countries that prefer the cheating option - the DWFNs - will argue for a treaty with low $\operatorname{Pr}_{D E T E C T}$ and/or a low fine. That is, they intend to play noncooperatively even after they have signed an agreement to cooperate. More generally, countries that wish for some reason to sign a treaty - an agreement to cooperate - while retaining their freedom of action (that is, to continue playing non-cooperatively) will argue for rules that create low values for the expected fine.

Supposing that a coastal state responsibly manages a straddling stock even

7 Arthur et al. (2019), discuss the effect of subsidies on increasing fishing effort.

8 This is the basic structure of many policing models that assume crime is deterred if the expected cost of crime is less than the expected benefit. Some authors point out that "non-economic" factors - such as loss of moral or social standing in a community, should also be considered as deterrence factors (see for example, Sumaila et al. (2006) and Hønneland (2001). However, in principle, it is possible to place pecuniary values on these 'non-economic' factors and these may also be subsumed under " $\mathrm{F}$ " in the preceding equation. 
if a DWFN cheats - as in Table 3. ${ }^{9}$ Because it wishes to continue playing a noncooperative game, the DWFN argues for low $P r_{D E T E C T}$ and/or a low fine. However, the CS wants sufficiently high values of these to deter cheating. Why then does the CS settle on a treaty with insufficiently high values of $\operatorname{Pr}_{D E T E C T}$ or $F$ ? The answer offered here is because the initial treaty is viewed as first step in a series of treaties - the Convention of 1982, the Agreement of 1995, and continuing negotiations in RFMOs after that. That is, CSs hope for a rising $P r_{D E T E C T}$ and/or $F$ through a series of steps.

It is also possible that neither side wishes responsibly to manage fish stocks, in which case both want low $\operatorname{Pr}_{D E T E C T} . F$. Why then does either bother to sign a treaty that they want to be ineffective? There must be other payoffs outside of the immediate game, e.g., to placate environmentalist lobbies who governments hope to fool with 'fine words'. For example, Balton (1996) and Stokke (2001) are of the view that environmentalist lobbies were a factor pushing the USA to sign the 1995 Agreement.

\section{A Broader Model of $E(F)$}

In practice, the expected fine depends on more than just $\operatorname{Pr}_{D E T E C T}$ and the size of the F. Other determinants include a) the probability that a fine will be levied after cheating has been detected. Here the results of bargaining over a disciplinary system matter - e.g., CS courts versus DWFNs courts, voluntary or compulsory arbitration of disputes, use of the International Court of Justice, use of exceptions by offending parties. And b) the size of a fine may depend on who is levying it a CS court or one in a DWFN.

An extended model of the expected fine is:

$$
E(F)=\operatorname{Pr}_{\text {DETECT }} \times \operatorname{Pr}_{\text {FINEIMPOSED }} \times\left[\alpha\left(F^{H I G H}+(1-\alpha) F^{L O W}\right]\right.
$$

where ' $\alpha$ ' is the probability of a high fine given that a fine is imposed. The size of the fine, high, or, low, can be assumed to depend on which state is imposing it: a CS, a DWFN, or, a third party, such as the International Court of Justice. According to the A Report of the Standing Senate Committee on Fisheries and Oceans (2003), disciplinary action through DWFNs is weak, implying either low $\operatorname{Pr}_{\text {FINEIMPOSED }}$ or low $\alpha$, or both. Moreover, a justifiable supposition is that a flag state has a lesser incentive to impose stiff 'fines' on violators than does a CS. A CS has an incentive to impose stiff penalties as a deterrent against future violations. A DWFN has lesser incentive both because its citizens benefit from illegal fishing on the high seas (profits, employment etc.) and, if it is a flag-of-convenience state,

9 This situation is like a law abiding household suffering crime, it does not turn to crime itself. 
it collects registration fees.

International bargaining covers all the elements in the last equation. For example: $P r_{D E T E C T}$ : does a CS have the right to board, to inspect below decks, to arrest with or without the permission of the flag state? Also, the ease of detecting depends on such things being in place as licensing (rendering the legality of fishing boat easier), and requirements to broadcast positions.

A possible method for increasing the $E(F)$ is through the extra-territorial application of domestic law and sanctions. For example, shipmasters could be licensed by their home state, and they would be required to report upon which vessels they are working (Erceg, 2006). Licenses could be withdrawn if a shipmaster was caught illegally fishing. Gallic and Cox (2006) favor "long arm" approaches which would allow for prosecutions of nationals for breaking foreign laws wherever they are committed. ${ }^{10}$ These types of sanction are aimed at raising the $E(F)$, especially $P r_{\text {FINEIMPOSED }}$. However, Erceg (2006) says that lack of cooperation from flag states would render the system largely ineffective. A problem with the Convention is that coastal states are not allowed to imprison fishers caught illegally fishing on foreign flagged vessels - indeed, the flag state can take over prosecutions at any time. A possible way around this is the use of bilateral Agreements between countries allowing coastal state prosecutions. But then, why would a DWFN agree to this?

\section{Optimal Spending on Policing}

Here 'expenditure on policing', E, means all expenditures related to policing - monitoring, surveillance, data collection and management, cost of positional devices, cost of licensing system, cost of running quota systems. In fact, all things that relate to the governance of a fishery. Use,

$$
\mathrm{E}(F)=\operatorname{Pr}_{D E T E C T}(E) \times F
$$

where $\operatorname{Pr}_{\text {DETECT }}(E)$ means that $P r_{D E T E C T}$ is a positive function of $\mathrm{E}$.

The gross gain from cheating on the vertical axis of Figure 1 is the payoff from cheating while others comply. It is a downward sloping function because 'investment in cheating' is assumed to increase as expenditure on policing rises (scaled on the horizontal axis). The $E(F)$ rises as expenditure on policing rises. $\mathrm{X}_{1}$ is the necessary minimum expenditure on policing to encourage compliance with

10 The US Lacey Act allows for this with respect to US nationals. Moreover, Section 104 of the US's High Seas Fishing Compliance Act of 1994 requires US fishing boats operating on the high seas to have the requisite permits, are clearly marked for identification purposes, to report their fishing activities, and not to breach international conservation agreements. Additional requirements were published in 2016 requiring fishing boats to have enhanced mobile transceivers for vessel monitoring, to carry onboard observers, to report transshipments happening on the high seas, and that vulnerable marine ecosystems should be conserved. 
a treaty's rules. If policing expenditure is less than $X_{1}$, the gross gain from cheating exceeds the expected fine and policing is not a deterrent to cheating.

Figure 1. Minimum effective spending on policing.

$\$$

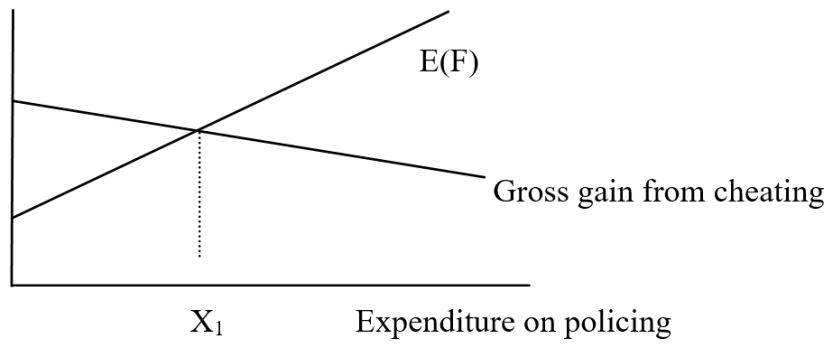

The treaty formation 'game' is to devise tools to achieve at least $\mathrm{X}_{1}$ through sufficient policing and sufficiently large fines.

\section{Policing Cost Versus Legitimacy}

Hønneland (2001) argues that if new institutional arrangements for the fishing of straddling stocks are viewed as 'legitimate' by DWFNs, policing costs would be reduced, and North (1981) observes that "The premium necessary to induce people to become free riders is positively correlated with the perceived legitimacy of the existing institutions" (p. 54). In other words, in the straddling stocks context, the more legitimate is a fishing regime, the more difficult it becomes to induce operatives, such as shipmasters, knowingly to break the law and, therefore, the more effective is the regime.

The fundamental problem still is to settle on rules that both DWFNs and shipmasters would find legitimate. Unfortunately, both the Convention and the Agreement built in loopholes as a matter of compromise between CSs and DWFNs. Examples are the right to use the objection, thereby freeing the objecting state from abiding by the clause-in-law objected to, and historical fishing rights, that have been used to justify DWFNs taking straddling stocks that thwart CS management of them within their EEZs. ${ }^{11}$ From the beginning, both the Convention and the Agreement were written with weak rules, or rules that would be ineffectively enforced - rendering low values of expected 'fines', largely because at least some fishing nations, most often DWFNs, did not think that a regime with tough rules that yielded high expected fines, was legitimate. Vicuña (1999) describes several examples of compromises that led to weak rules that

11 Canada as the coastal state has often faced this problem in the NAFO. 
essentially meant that $\mathrm{E}(\mathrm{F})$ is insufficiently high. ${ }^{12}$

The sort of compromises made between CSs and DWFNs that rendered the Agreement weak is illustrated by the negotiations over the rules governing investigation and prosecution of fishing violations. With respect to prosecution, in the draft Agreement a coastal state could prosecute a violator with the concurrence of the flag state. The final text though has no reference to prosecution by an arresting coastal state, while it is the DWFN that has the right to take any measures, including proceedings to impose penalties, according to its laws - Article 21 (3). So it is that a DWN can step in at any time to take over a case against a suspected DWFN violator.

\section{Repeated Game Aspects}

A question asked earlier is why would a country sign and ratify a treaty that it knows will be ineffective, or, once it finds out that it is ineffective, it does not withdraw from the treaty and its institutions? The case of Canada, and the NAFO is a case in point, as Canada has become disillusioned over the ineffectiveness of NAFO. Non-compliance with NAFO rules includes directed or intentional fishing for species under moratoria; exceeding quotas; misreporting catches, by area and species; improper use of fishing gear (e.g., mesh sizes); fishing in areas closed to fishing; failure to maintain independent and impartial fisheries observers; and interference with NAFO inspectors, observers, or evidence. ${ }^{13}$ To quote from the Canadian Report of the A Report of the Standing Senate Committee on Fisheries and Oceans (2003):

"There have been calls for Canada to withdraw from NAFO (the Northwest Atlantic Fisheries Organization), an option usually made in conjunction with another proposal: the establishment of a new "Canadian custodial management" regime outside the 200-mile limit ... The two are typically linked because, with nothing else to replace NAFO, simply leaving would be self-defeating, and the consequences unacceptable. Indeed, witnesses strongly opposed the option for a number of reasons. For example, the problem of non-compliance would [be] more widespread because there would be less enforcement. Canada would no longer benefit from information obtained from the observer program, the inspections and surveillance scheme, and vessel monitoring. There would no longer be an international forum for discussion of issues with the other countries. The

12 Vicuña (1999) points out that the Agreement is based on "genuine compromise" (p. 290) and that it combines "the advancement of basic principles [of conservation] with the necessary safeguards as to the existing rights and arrangements" (p. 290).

13 See A Report of the Standing Senate Committee on Fisheries and Oceans, 2003. 
remaining countries would be unlikely to offset Canada's large financial contributions to NAFO's budget, which could lead to the dismantling of NAFO and an unregulated fishery."

And, bearing out the main point made in this paper, namely that coastal states see themselves in a game with distant water nations:

"The very strong consensus in our deliberations was that it is much better for Canada to have an imperfect, internationally agreed upon regime, such as NAFO, than no regime at all."

The Committee went on to identify several instruments that could in the future be used to improve the effectiveness of NAFO management on the Grand Banks, that is to make the NAFO international fisheries Agreement more effective by writing in new clauses. Thus,

“The Objection Procedure, which is the major flaw in NAFO's Convention, could be modified or removed altogether. As previously mentioned, any member of the Fisheries Commission who presents an objection to a NAFO proposal within the required time limit is not bound by the measure, and there is no limitation on the number of objections that can be made or on the type of proposal to which an objection may relate."

And

"Other proposals to improve NAFO include: according the Scientific Council greater influence in decision-making; giving countries with a greater economic and conservation interest in NAFO a greater say in decision-making (e.g., with a system of weighted voting); incorporating the precautionary and ecosystem approaches (enunciated in UN FAO) into the NAFO Convention; adopting a "ships of shame policy" (publishing a list of rogue ships, banning them from the Regulatory Area); harmonizing the sanctions regime; adopting a dispute settlement system; and even perhaps delegating fisheries enforcement to a new NAFO agency ... But reforming the operation of NAFO will depend on whether there is sufficient political will on the part of its members to affect change. From what we heard [in our hearings], coalition-building and getting the required political will may not be easy".

Thus, at least Canada is prepared for new rounds of the CSs versus DWFNs game with the express objective of raising $\mathrm{E}(\mathrm{F})$. 


\section{Conclusion}

The main question asked in this paper is why do countries knowingly sign ineffective fishing Agreements? The answer is that they are part of an incomplete repeated game between coastal states on the one side, and distant water fishing nations on the other. It is argued that distant water fishing nations want ineffective management of straddling stocks so that they can continue to play a noncooperative game in which they are concerned only with their own payoffs, rather than with the broader global social interest especially the interests of coastal states. Coastal states signed the largely ineffective Convention of 1982 and Agreement of 1995 because they gained their own EEZs. The ineffective part of the Convention - that concerned with the management of straddling stocks, coastal states saw as only a first step in would be a repeated game; the Agreement being the second, and also inconclusive step. Coastal states hoped, and still do, to bring this repeated game to a satisfactory conclusion, possibly from ongoing negations in the many regional fish management organization. But these negotiations, even 40-years after the finalization of the Convention and 26-years after the finalization of the Agreement, still have a long way to go.

What is needed to improve high seas fisheries management is better surveillance, increased sanctions, and enhanced collaboration between states. The most fundamental change would be to modify treaty law to remove claims for exceptions - e.g., against fishing quotas, but this will not happen because treaty law, as under the Vienna Convention on the Law of Treaties, is seen as a fundamental right of nations. However, smaller steps could be taken either within the regional fish management organizations, or bilaterally between pairs of coastal states and distant water fishing nations. As a first step, to encourage better surveillance by coastal states, any fines levied in a distant water fishing nation's court could be transferred to the coastal state that has been offended against. A bigger step would be to agree to transfer prosecutions from the courts of distant water fishing nations to those of coastal states. This would likely increase the probability that fines would be imposed, that they would be large fines, and in serious cases, even imprisonments could be enforced. Compulsory arbitration in an international body such as the International Court of Justice, or in a newly created 'fisheries court', could be agreed to. And shipmasters could be required to report on which vessels they are working and to have their licenses withdrawn if caught overfishing.

\section{References}

Arthur, R., Heyworth, S., Pearce, S. J., and Sharkey, W. (2019) The Cost of Harmful 
Fishing Subsidies. London: International Institute for Environment and Development.

Balton, D. A. (1996) Strengthening the Law of the Sea: The New Agreement on Straddling Fish Stocks and Highly Migratory Fish Stocks. Ocean Development and International Law, 27(1-2):125-151.

Boyle, A. E. (1999) Problems of Compulsory Jurisdiction and the Settlement of Disputes Relating to Straddling Fish Stocks. The International Journal of Marine and Coastal Law, 14(1):1-25.

Cullis-Suzuki, S. and Pauly, D. (2010) Failing the High Seas: A Global Evaluation of Regional Fish Management Organizations. Marine Policy, 34(5):1036-1042.

Eckert, R. D. (1979) The Enclosure of Ocean Resources. Standord, CA: Hoover Institution Press.

Erceg, D. (2006) Deterring IUU Fishing through State Control over Nationals. Marine Policy, 30(2):173-179.

Flewwelling, P. and Cullinan, C. (2000) Guide to Monitoring, Control and Surveillance Systems for Coastal and Offshore Capture Fisheries. FAO Fisheries Technical Paper No. 500. Rome: FAO.

Food and Agricultural Organization. (2006) General Situation of World Fish Stocks. Rome: FAO.

Gagern, A. and van den Bergh, J. (2013) A Critical Review of Fishing Agreements with Tropical Developing Countries. Marine Policy, 38:375-386.

Gallic, B. L. and Cox, A. (2006) An Economic Analysis of Illegal, Unreported and Unregulated (IUU) Fishing: Key Drivers and Possible Solutions. Marine Policy, 30(6):689-695.

Hallwood, P. (2013) Piracy and the Law of the Sea: An Empty Vessel? School of Advanced International Study (SAIS). Review of International Affairs, 33(2):117-126.

Hallwood, P. (2014) Economics of the Oceans: Rights, Rents and Resources. Abingdon: Routledge.

Hannesson, R. (1995) Fishing on the High Seas: Cooperation or Competition. Marine Policy, 19(5):371-377.

Hønneland, G. B. (2001) Recent Global Agreements on High Seas Fisheries: Potential Effects on Fisherman Compliance. Lysaker, Norway. pp. 121-139.

Kaitala, V. and Lindroos, M. (1998) Sharing the Benefits of Cooperation in High Seas Fisheries: A Characteristic Function Game Approach. Natural Resource Modeling, 11(4):275-299.

Munro, G. R. (2009) Game Theory and the Development of Resource Management Policy: The Case of International Fisheries. Environment and Development Economics, 14(1):7-27.

North, D. C. (1981) Structure and Change in Economic History. New York, NY: W.W. 
Norton.

Romano, C. (2001) The Southern Bluefin Tuna Dispute: Hints of a World to Come ... Like it or Not. Ocean Development \& International Law, 32(4):313-348.

Schiller, L., Bailey, M., Jacquet, J., and Sala, E. (2018) High Seas Fisheries Play a Negligible Role in Addressing Global Food Security. Sciences Advances, 4(8):aat8351.

Springer, A. L. (1997) The Canadian Turbot War with Spain: Unilateral State Action in Defense of Environmental Interests. Journal of Environment \& Development, 6(1):26-60.

Standing Senate Committee on Fisheries and Oceans. (2003) Straddling Fish Stocks in the Northwest Atlantic. Retrieved from http://www.parl.gc.ca/37/2/parlbus/commbus/ senate/Com-e/fish-e/rep-e/rep05jun03e.htm\#A.\%20\%20The\%201982\%20United

Stokke, O. S. (2001) Governing High Seas Fisheries: The Interplay of Global and Regional Regimes. Oxford: Oxford University Press.

Sumaila, U. R., Alder, J., and Keith, H. (2006) Global Scope and Economics of Illegal Fishing. Marine Policy, 30(6):696-703.

Sydnes, A. K. (2001) Regional Fishery Organizations: How and Why Organizational Diversity Matters. Ocean Development and International Law, 32(4):349-372.

Sea Around US. (2021). We Present Fisheries and Fisheries-related Data at Spatial Scales that have Ecological and Policy Relevance, such as by Exclusive Economic Zones, High Seas, or Large Marine Ecosystems. Retrieved from http://www.seaaroundus.org

United Nations. (2021) Chronological Lists of Ratifications of, Accessions and Successions to the Convention and the Related Agreements. Division for Ocean Affairs and Law of the Sea. Retrieved from https://www.un.org/depts/los /reference_files/chronol ogical_lists_of_ratifications.htm

United States Department of State. (2021) The Agreement to Prevent Unregulated High Seas Fisheries in the Central Arctic Ocean Enters into Force. Washington, DC: United States Department of State.

Vicuña, F. O. (1999) The Changing International Law of High Seas Fisheries. Cambridge: Cambridge University Press. 
